\title{
Pharmacist Involvement in the Emergency Room in Selecting Antibiotics for Trauma Patients
}

\author{
Brittany L Riley ${ }^{1 *}$, Stephen J Cook ${ }^{2}$ and Janet Wolcott ${ }^{1}$ \\ ${ }^{1}$ Pharmacy Practice and Administration and Research, Marshall University School of Pharmacy, United States \\ ${ }^{2}$ University of Charleston, Department of Pharmacy Practice, United States
}

Received: October 24, 2013; Accepted: December 20, 2013; Published: December 24, 2013

"Corresponding author: Brittany L Riley, Pharmacy Practice and Administration and Research, Marshall University School of Pharmacy, United States, Tel: 304-696-7396; E-mail: warrick2@marshall.edu

\begin{abstract}
Objectives: To determine the impact that the presence of a pharmacist has on the care a trauma patient in the emergency department.

Methods: Single center, retrospective, observational study that assessed the charts of all trauma patients that presented as Priority 1 or Priority 2 trauma alerts from December 1, 2009-November 30, 2010. Patients were separated into two categories, pharmacist present and pharmacist not present. Patient age, gender, weight, past medical history, allergies and injuries sustained from trauma, medications given during trauma, and time from arrival to administration of medications.
\end{abstract}

Results: 508 charts were included in this study. Pharmacists were present for $26 \%$ of these patients. When the pharmacist was present it was more likely that the patient received the appropriate dose of antibiotic ( $99 \%$ vs $79 \%$, p-value $<0.05)$. In adult patients when the pharmacist was present the antibiotics were given faster (17.9 min vs $36.6 \mathrm{~min}$, p-value $<0.05$ ).

Conclusion: The presence of pharmacists at trauma alerts can improve the care that trauma patients receive.

Keywords: Trauma; Pharmacist involvement; Pharmacy services

\section{Background}

Traumatic injury is a common cause of death and debilitation in the United States. Unintentional injury is the leading cause of death if people aged 1-44 years and the fifth leading cause of death in all age groups [1]. There are several classes of medications that are commonly used in patients experiencing a traumatic injury. These include antibiotics, analgesics, sedatives and antiepileptic. The purpose of this study was to determine if pharmacists have a positive impact the appropriate use of antibiotics in emergency room traumas.

There is a recent increase in the presence of Emergency Department pharmacists across the United States that is able to provide pharmaceutical care to trauma patients while they are still in the trauma bay. There are also several institutions, that although they do not have a dedicated ED pharmacist, that do have clinical pharmacists who are trained to respond to trauma alerts, much like response to cardiac arrests in the hospital. The type of interventions pharmacists make during traumas have been studied previously [2]. The impact on patient care has not been adequately studied.

Cabell Huntington Hospital (CHHI) is a 315 bed teaching hospital and a Level II trauma center for both adult and pediatric patients. CHHI services counties in West Virginia, Ohio and Kentucky and serves as the primary referral center for a good percentage of these states. At CHHI clinical pharmacists or pharmacy residents respond to trauma alerts from 7:00 am to 7:00 pm. Pharmacy residents are only allowed to attend trauma alerts independently with the oversight of a clinical pharmacist after the resident has proven to meet the competency standards for response to trauma alerts. There is a core group of clinical pharmacists that are tasked with response to trauma alerts, and they all have went through the same training and competency process before response to trauma alerts. The pharmacist's main function at trauma alerts is pharmacotherapy recommendations, allergy checks, and medication preparation. The majority of pharmacotherapy recommendations are directed at antibiotic and antiepileptic therapy warranted by patient presentation.

Each institution has their own variation of ways to classify the severity of a trauma patient presenting to the emergency department. At CHHI there is a two-tiered approach. The lowest tier is a Priority 2 trauma alert. These consist of patients who meet the criteria for a trauma alert primarily based on mechanism of injury (motor vehicle collision, penetrating injury, etc). The majority of the time these patients are very low acuity. The higher tier is a Priority 1 trauma alert. The criteria for this level is a Glasgow Coma Scale less than 8, a penetrating injury that is located from the chest area through the abdomen area, and respiratory/hemodynamic compromise. Essentially, when comparing a Priority 1 verse a Priority 2, the priority 1 is the most likely to need immediate transport to the operating room.

\section{Methods \\ Study design}

This study was a single center, retrospective, observational 
study designed to examine the impact of the pharmacist on antibiotic use at trauma alerts. Antibiotics were the focus of the data collection due to the practice at the institution. The majority of the patients that present to CHHI as a trauma alert present via medical air transport and have often received sedative and analgesic medications prior to arrival in the trauma bay. Electronic medical records of patients that presented as either Priority 1 or Priority 2 trauma alerts were examined and the following data collected: presenting injuries, antibiotic medication doses and time of administration, and the presence of a pharmacist. All of this information came from the trauma flow sheet, which serves as the official record of the care trauma patients receive from the time they enter the emergency department to the time they are transferred to the operating room or floor or are discharged from the hospital. The study was approved by the Marshall University Institutional Review Board.

\section{Inclusion/Exclusion}

Trauma patients that presented to the emergency department from December 1, 2009 - November 30, 2010were eligible for review. Patients of all ages were included in the study. Trauma subjects were only excluded if a trauma flow sheet was not present in the electronic medical record.

\section{Data collection and analysis}

Patients were separated into two categories: pharmacist present and pharmacist not present. Patient age, gender, and weight were collected to determine appropriate medication dosing. Past medical history, allergies, and trauma injuries were recorded to assess appropriate antibiotic and antiepileptic selection. Timing of medication administration was collected to assess time from trauma arrival to medication administration.

Pharmacists respond to traumas during the twelve hour day and pharmacists are not available to respond at night. The data was analyzed to compare the effects pharmacists had on antibiotic selection in regards to trauma injuries, allergies, and past medical history. The same concept was used to determine if pharmacists have an impact on appropriate dosing and timely administration. The trauma physician or resident was responsible for medication selection and dosing when a pharmacist was not present. If a pharmacist was present then he or she would recommend specific pharmacologic therapies or recommend certain therapies be avoided. Ultimately the physician or surgical resident would accept or reject pharmacy recommendations.

The East trauma guidelines were used to assess the appropriate use of antibiotics and antiepileptic [3-6]. Some trauma injuries are not covered within the East guidelines. In this case primary literature was reviewed to determine if were recommended [7-9]. Table 1 and 2 summarizes what was determined to be appropriate use of pharmacotherapy. Patient specific factors, such as weight and age, where taken into consideration when determining if the dosing was appropriate or not. For example, a $1 \mathrm{~g}$ cefazolin dose in a $100 \mathrm{~kg}$ patient would be deemed inappropriate. Another example would be the aminoglycosides, for which doses from $5-7 \mathrm{mg} / \mathrm{kg}$ adjusted body weight would be considered appropriate.

\begin{tabular}{|l|l|}
\hline Trauma Injury & Acceptable Antibiotic or Antiepileptic \\
\hline $\begin{array}{l}\text { penetrating } \\
\text { abdominal wound }\end{array}$ & $\begin{array}{l}\text { clindamycin + aminoglycoside } \\
\text { ampicillin/sulbactam } \\
\text { piperacillin/tazobactam } \\
\text { ertapenam } \\
\text { cefoxitin or cefotetan } \\
\text { metronidazole + aminoglycoside }\end{array}$ \\
\hline Grade I-II open fracture & $\begin{array}{l}\text { nafcillin } \\
\text { cefazolin } \\
\text { clindamycin }\end{array}$ \\
\hline Grade III open fracture & Grade II coverage + aminoglycoside \\
\hline $\begin{array}{l}\text { laceration } \\
\text { (excluding uncomplicated) }\end{array}$ & $\begin{array}{l}\text { cefazolin } \\
\text { clindamycin } \\
\text { nafcillin }\end{array}$ \\
\hline $\begin{array}{l}\text { farming (fecal } \\
\text { contamination) }\end{array}$ & penicillin G \\
\hline
\end{tabular}

Table 1: Acceptable Prophylaxis ${ }^{3-9}$.

clindamycin 600-1200 mg

gentamicin/tobramycin $5-7 \mathrm{mg} / \mathrm{kg}$ (adjusted body weight)

ampicillin/sulbactam 2000-3000 mg

piperacillin/tazobactam 3.375-4.5 grams

ertapenam 1 gram

cefoxitin or cefotetan 1-2 grams

metronidazole $500 \mathrm{mg}$

nafcillin 1-2 grams

cefazolin1-2 grams

penicillin G 4-6 million units

Table 2: Acceptable Dosing ${ }^{3-9}$.

Each patient's chart was reviewed by a single pharmacist. When there were questions about true appropriateness a second pharmacist was consulted to determine if the course of action was appropriate or not. Categorical data was analyzed using a ChiSquare test and continuous data was analyzed using a Student's T-Test. All statistical analysis was performed using Excel@ and the XLStat $(\subset)$ add-in for Excel@ $C$.

\section{Results}

Table 3 shows the baseline demographics for the two groups. Of interest, patients were older in the pharmacist present group and were more likely to be a priority 1 trauma. This suggests that patients were more complex in the pharmacist present group when compared to the pharmacist not present group. Figure 1 shows the mechanism of injury that was recorded for each patient. Data on the exact injuries sustained was not available from the trauma flow sheet, only data on the presentation (location and type of external injuries) was available as the study only looked at what would be available to those practitioner's in the trauma bay.

Table 4 reports the results found for the entire group of patients studied. In the pharmacist present group $48 \%$ received antibiotics compared to $28.3 \%$ of patient in the not present group ( $p$-value $=0.0003$ ). The most common reasons that patients received antibiotics were lacerations and open fractures. There was not a significant difference found when looking at the appropriateness of the antibiotic selection between the groups ( $87.5 \%$ vs $78 \%$, p-value $=0.132) .99 \%$ of the patients received an 
appropriate dose of antibiotic when a pharmacist was present compared to $79 \%$ of the patients when a pharmacist was not present $(p$-value $=0.00006)$. This was mostly driven by dosing of amino glycosides for open fractures. An antibiotic was omitted $1.23 \%$ of the time when a pharmacist was present compared to $20.5 \%$ of the time when a pharmacist was not present ( $p$-value $=0.00000000001$ ). The mean time to first dose of antibiotic when a pharmacist was present was 17.9 minutes and 36.6 minutes ( $\mathrm{p}$-value $=0.01)$.

Table 5 reports the results found for the pediatric patients included in the study. In the group that a pharmacist was present $37 \%$ of patients received antibiotics and $18.9 \%$ of patients received an antibiotic when a pharmacist was not present ( $\mathrm{p}$-value $<0.015)$. When a pharmacist was present an antibiotic was never omitted compared to $23.0 \%$ of the time when a pharmacist was not present ( $p$-value $<0.0002$ ). No other measure was found to be statistically significant.

\section{Discussion}

Pharmacist's participation on trauma teams has been studied. This study found that pharmacists do have a role in the care of trauma patients. In this study, it was found that antibiotic use at trauma alerts is positively impacted by a pharmacist's presence. When a pharmacist is present a patient is more likely to receive the appropriate dose of an antibiotic and to receive the antibiotic in a more timely fashion. The time to first dose antibiotic is an important factor to consider, as many of these patients do go

\begin{tabular}{|l|l|l|l|}
\hline & $\begin{array}{l}\text { Pharmacist } \\
\text { Present n=137 }\end{array}$ & $\begin{array}{l}\text { Pharmacist not } \\
\text { present n=371 }\end{array}$ & P-Value \\
\hline $\begin{array}{l}\text { Age (mean in } \\
\text { years) (SD) }\end{array}$ & $37.8(19.3)$ & $32.3(17.6)$ & 0.0013 \\
\hline Males & $114(83.2 \%)$ & $263(70.9 \%)$ & 0.74 \\
\hline Priority 1 & $35(25.5 \%)$ & $43(11.6 \%$ & 0.0032 \\
\hline
\end{tabular}

Table 3: Baseline Demographics.

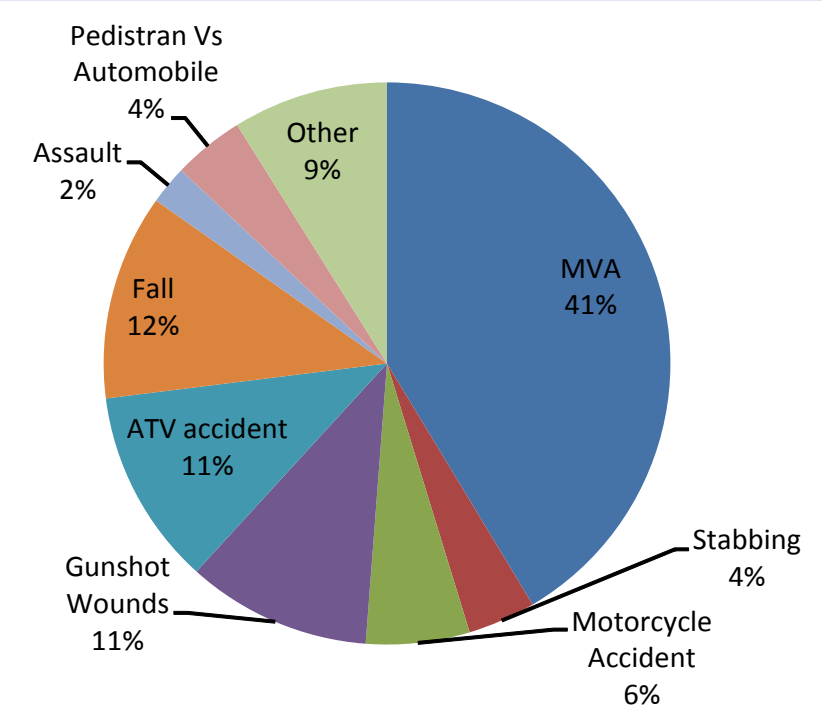

Figure 1: Mechanism of Injury.

\begin{tabular}{|l|l|l|l|}
\hline & $\begin{array}{l}\text { Pharmacist } \\
\text { Present n=167 }\end{array}$ & $\begin{array}{l}\text { Pharmacist not } \\
\text { present } \\
\text { n=371 }\end{array}$ & P Value \\
\hline Antibiotic Given & $80(48 \%)$ & $105(28.3 \%)$ & 0.0003 \\
\hline $\begin{array}{l}\text { Antibiotic } \\
\text { Appropriate }\end{array}$ & $70(87.5 \%)$ & $83(78 \%)$ & 0.132 \\
\hline $\begin{array}{l}\text { Dose of } \\
\text { Antibiotic } \\
\text { Appropriate }\end{array}$ & $79(99 \%)$ & $83(79 \%)$ & 0.00006 \\
\hline $\begin{array}{l}\text { Omission of } \\
\text { Antibiotic }\end{array}$ & $1(1.23 \%)$ & $76(20.5 \%)$ & 0.00000000001 \\
\hline $\begin{array}{l}\text { Time to } \\
\text { Antibiotic Given } \\
\text { (minutes) (SD) }\end{array}$ & $17.7(18.9)$ & $36.6(38.9)$ & 0.01 \\
\hline
\end{tabular}

Table 4: Results for all patients.

\begin{tabular}{|l|l|l|l|}
\hline & $\begin{array}{l}\text { Pharmacist } \\
\text { Present } \mathbf{n}=\mathbf{4 3}\end{array}$ & $\begin{array}{l}\text { Pharmacist } \\
\text { Not Present } \\
\mathbf{n = 1 2 2}\end{array}$ & P-Value \\
\hline Antibiotic Given & $16(37.0 \%)$ & $23(18.9 \%)$ & 0.015 \\
\hline $\begin{array}{l}\text { Antibiotic } \\
\text { Appropriate }\end{array}$ & $12(75.0 \%)$ & $20(87.0 \%)$ & 0.338 \\
\hline $\begin{array}{l}\text { Dose of } \\
\text { Antibiotic } \\
\text { Appropriate }\end{array}$ & $14(87.5 \%)$ & $18(78.3 \%)$ & 0.460 \\
\hline $\begin{array}{l}\text { Omission of } \\
\text { Antibiotic }\end{array}$ & $0(0.0 \%)$ & $28(23.0 \%)$ & 0.0002 \\
\hline $\begin{array}{l}\text { Timing to } \\
\text { Antibiotic } \\
\text { (minutes) (SD) }\end{array}$ & $20.7(32.1)$ & $33.1(32.8)$ & 0.307 \\
\hline
\end{tabular}

Table 5: Results for pediatric patients.

directly from the emergency department to the operating room and timing of preoperative antibiotics is an important factor to consider. . In the pediatric population, there was not the same difference in timing of antibiotics as saw in the general population. This is most likely because of the need to compound special pediatric concentrations of antibiotics.

The original study design was not formulated to find the financial impact pharmacists could have pertaining to medication selection. Certain broad spectrum antibiotics are appropriate according to literature and EAST Trauma guidelines, however are not always necessary. Pharmacist that responded to traumas also recommended narrower spectrum antibiotics that could potentially decrease medication usage cost while providing the same infectious prophylactic benefit. This study did not attempt to find any potential cost benefit of pharmacists responding to traumas, but this may be further explored based on the results of this study.

This study did have some limitations associated with it. The first is the retrospective nature. The investigators were relying on the documentation done by the nursing staff and physicians. There were several instances where information was not recorded in a manner which made it easy for the investigators to determine if the care provided was appropriate or not. Also, this made it difficult to determine what the final injuries were for the patients because often only the presentation is documented 
on the flow sheets. In these instances the records were reviewed by two independent investigators to deem appropriateness. The second and biggest limitation of this study is the fact that the data is skewed towards the no pharmacist present group. Around $2 / 3$ of the study population fell in the no pharmacist present group. This increased our chance of not finding a difference, when one may have existed. A third limitation is that is currently impossible to determine if the results found in this study were due to practice differences between the AM and PM shifts. It is important to note however, that the primary providers who provide care to trauma patients do not differ based on this shift as they are typically on call for the entire 24 hour period. The only staff that differs is the main pharmacy staff responsible for the preparation of medications not available in the Emergency Department and the nursing staff.

\section{Conclusion}

This study showed that pharmacists do have a positive impact on the care a trauma patient receives while still in the trauma bay. It also is a testament to the fact that clinical pharmacy services in this area needs to be expanded such that more patients would be able to benefit from a the services a pharmacist can provide. Furthers studies should be conducted to decrease the impact of the above mentioned confounders and to determine the cost effectiveness of a pharmacist on the trauma team.

\section{References}

1. www.cdc.gov/injury/wisqars/pdf/10LCID_All_Deaths_By_Age_ Group_2010-a.pdf
2. Patanwala AE, Hays DP (2010) Pharmacist's activities on a trauma response team in the emergency department. Am J Health Syst Pharm67(18): 1536-1538.

3. EAST Practice (1998) Parameter Workgroup for Penetrating Colon Injury Management. Patient management guidelines for penetrating intra peritoneal colon injuries. Eastern Association for the Surgery of Trauma.

4. Luchette FA, Barrie PS, Oswanski MF, Spain DA, Mullins CD, et al (2000) Practice Management Guidelines for Prophylactic Antibiotic Use in Tube Thoracostomy for Traumatic Hemopneumothorax: the EAST Practice Management Guidelines Work Group. Eastern Association for Trauma. J Trauma 48(4): 753-757.

5. Hoff WS, Bonadies JA, Cachecho R, Dorlac WC (2011) East Practice Management Guidelines Work Group: update to practice management guidelines for prophylactic antibiotic use in open fractures. J Trauma $70(3): 751-754$.

6. EAST Practice (2000) Management Guidelines Workgroup. Practice management guidelines for prophylactic antibiotic use in open fractures. Eastern Association for the Surgery of Trauma.

7. Gillespie WJ, Walenkamp G (2010) Antibiotic prophylaxis for surgery for proximal femoral and other closed long bone fractures. Cochrane Database Syst Rev (3): 1-67.

8. Chang BS, Lowenstein DH (2003) Practice parameter: Antiepileptic drug prophylaxis in severe traumatic brain injury: Report of the Quality Standards Subcommittee of the American Academy of Neurology. Neurology 60(1): 10-16.

9. Schierhout G, Roberts I (1998) Prophylactic antiepileptic agents after head injury: a systematic review. J Neurol Neurosurg Psychiatry 64(1): 108-112. 